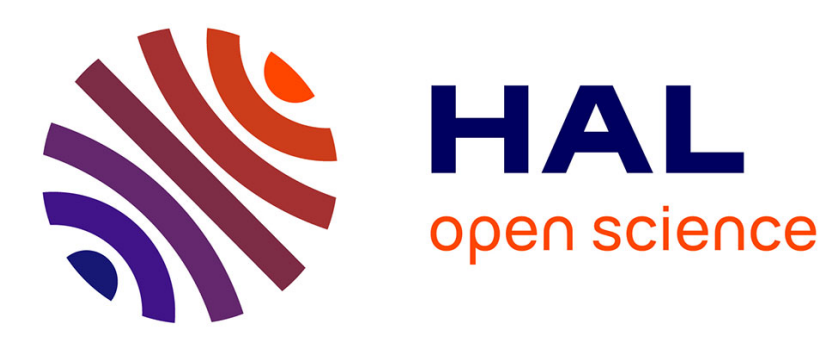

\title{
Paths in L2 Acquisition: The Expression of Temporality in Spatially Oriented Narration
}

Annie-Claude Demagny

\section{To cite this version:}

Annie-Claude Demagny. Paths in L2 Acquisition: The Expression of Temporality in Spatially Oriented Narration. Multilingual Matters. Comparative Perspectives on Language Acquisition - A tribute to Clive Perdue, Multilingual Matters Publisher, pp.482-501, 2012, Second Language Acquisition, 978-184769-603-8. hal-01012037v2

\section{HAL Id: hal-01012037 https://hal.science/hal-01012037v2}

Submitted on 4 Nov 2019

HAL is a multi-disciplinary open access archive for the deposit and dissemination of scientific research documents, whether they are published or not. The documents may come from teaching and research institutions in France or abroad, or from public or private research centers.
L'archive ouverte pluridisciplinaire HAL, est destinée au dépôt et à la diffusion de documents scientifiques de niveau recherche, publiés ou non, émanant des établissements d'enseignement et de recherche français ou étrangers, des laboratoires publics ou privés. 
Paths in L2 Acquisition:

The Expression of Temporality in Spatially oriented Narration*

Annie-Claude Demagny

SFL \& the University of Paris 8

\section{Introduction}

Research into the expression of temporality in L2 acquisition has been sufficiently extensive over the last 30 years to allow for generalizations (see, Dietrich, Klein \& Noyau 1995; Klein \& Perdue 1997; Carroll, Natale \& Starren 2008; Bartning \& Schlyter 2004; Bardovi-Harlig 1995, 1999, 2000; Shirai \& Kurono 1998; Andersen \& Shirai 1994, 1996). These studies have led to a more detailed definition of the stages and paths followed by learners during L2 acquisition, particularly in the area of temporality, where two theories have been proposed: the Defective Tense Hypothesis (DTH) and the Aspect Hypothesis. Yet, the interaction between the spatial and temporal domains, which are closely related in language, has rarely been addressed. In the present study, this relation is examined among learners at different competence levels during their acquisition of a foreign language. Specifically, this study aims to examine the expression of temporality in discourse involving numerous references to motion events as well as requiring the expression of simultaneity.

The speakers examined were young adults, native speakers of English, who are studying French L2 in a semi-guided context in France. These learners were confronted to different typological properties of their source language (English) and target language (French). The two languages differ in several respects that are central to our study. First, they belong to two language families which employ distinct ways of expressing of motion,

I would like to thank M. Hickmann, H. Hendriks, S. Benazzo and M. Watorek for their valuable advice. 
known as satellite- and verb-framed languages ( $c f$., Talmy 2000). Aspectual marking also differs between the two languages. Verbal marking in English presents a more symmetrical and transparent system compared to French. We examine the implications of these cross-linguistic differences for second language acquisition in the spatial and temporal domains as reflected in the production of narratives. The narrative discourse used WAS designed to collect data on voluntary and caused motion that invited speakers to describe events that included both different paths and different manners of motion in the same temporal region.

\section{Typological perspectives}

\section{Temporal-aspectual marking: general properties}

Most traditional grammars define temporality along a temporal axis that progresses from past to future, through the present. Various relations between situations can be added to this linear perspective, such as temporal jumps (virtual or real) and overlaps (inclusion, complete or partial simultaneity). The present is considered a central reference point that corresponds to the moment of speech, from which the timing of an event is measured. In this way, a past event can be situated as preceding the moment of speech and a future event as following that moment, although the future should be considered as a modality, since, unlike the past, a future event has not yet taken place at the moment of speech.

Verbal morphology in the languages studied (English and French) distinguishes both tenses and aspectual markings. Grammatical aspect can be defined as providing ways of presenting situations either as a point without internal structure (the perfective) or as an ongoing interval (imperfective). This category of languages distinguishes different phases of events: the initial phase, or left boundary, which marks the beginning of a situation (elle commence à manger 'she starts to eat'); the final phase, or right boundary (elle a fini de manger 'she finished to eat', elle a mangé 'she ate'), which marks the end of a situation; 
and the intermediary phase, the interval between the two boundaries; English expresses the intermediary phase by means of the progressive in all tenses (she is/was eating), while French does so differently depending on tense: it uses the imparfait in the past (elle mangeait 'she ate'), but the present is not marked for grammatical aspect (elle mange 'she eats'), requiring a periphrastic construction (elle est en train de manger 'she is in the process of eating').

The semantic properties of verbs also contribute to the expression of aspectual distinctions. Thus, the verb traverser ('to cross') implies an endpoint, but the verb marcher ('to walk') does not; the presence of additional elements in the predicate can modify the aspectual properties of a verb: elle a couru jusqu'à la barrière ('she ran up to the barrier') is bounded, while elle a couru dans les bois ('she ran in the woods') is not. Lexical and grammatical aspect interact in language. Specifically, bounded verbs are incompatible with temporal devices that express duration and/or an interval (*elle traverse longtemps 'she crosses a long time') and inversely, unbounded verbs are incompatible with temporal elements that express a boundary (*elle court en trois heures 'she runs in three hours').

\section{Space and Time in English and French}

Following Talmy's typology (200) concerning the spatial domain, English belongs to the set of satellite-framed languages, in which manner of motion is prototypically expressed through the verb root while path is expressed by other elements: particles, prepositional phrases, adverbials or adjectivals. In contrast, French belongs to the family of verbframed languages, in which path is expressed through the verb and manner is expressed through an adverbial or a peripheral construction, frequently realized as a subordinate verbal form that may not be marked for tense and/or aspect (such as gerunds or infinitives).

In the temporal domain, the verbal morphology of English allows imperfective progressive forms in all tenses (past and non-past), thereby forming a relatively 
transparent system. Furthermore, since English is a satellite-framed language, the marking of boundaries in the expression of motion is frequently connected to spatial particles or prepositional expressions in the verbal network. Examples (1) and (2) illustrate the spatio-temporal role of these markers, which direct the speaker to use a spatial particle or preposition to express boundaries in the verbal network. In fact, the expressions across in (1) and up to the top in (2) indicate both a path and a boundary simultaneously, regardless of other forms marking tense (present, past) or aspect (progressive, non-progressive)

(1) She pushed her bicycle across the road. /She's pushing her bicycle across the road.

(2) She's walking all the way up to the top of it./ She was walking all the way up to the top of it.

French morphology marks the distinction between perfective and imperfective aspect only in the past by means of two distinct forms (elle a mangé (passé composé) / elle mangeait (imparfait)). However, unlike English, this distinction is not morphologically marked in the present, therefore requiring the use of a periphrastic construction (elle est en train de manger 'she is in the process of eating') or of a subordinate clause (such as a gerund: en mangeant 'while eating') to express simultaneity and/or imperfective aspect (see, Riegel, Pellat \& Rioul, 1999, p.339-341). As noted above, the expression of a change of location is tightly linked to the use of path verbs, verbs which frequently incorporate a left boundary in their lexical meaning. As illustrated in (3), French speakers do not need to add boundaries through satellite constructions, in contrast to English speakers. However, it is harder for French speakers to express both path and manner of motion syntactically in a single clause, thus motivating the use of a gerund to express the simultaneity of these two sub-events (4). The same example also illustrates the morphological-aspectual contrast with English (cf., ex. (1) and (2)).

(3) Elle a traversé la rue. (perfective) 'she crossed the street' 
(4) Popi descend la colline (unmarked aspect) en poussant la valise (imperfective).

'Popi goes down the hill, while pushing the suitcase'

\section{Implications for acquisition and hypotheses}

These differences in the temporal and spatial properties of the two languages raise questions regarding the paths of acquisition followe by English speaking learners of French. First, given the tendency in English to express manner of motion in the verbal root, the expression of path incorporated into the French verb is likely to constitute a stumbling block for learners (see, Hendriks et al., 2008).

In addition, these learners are expected to encounter particular difficulties in the expression of temporal boundaries, since they cannot always rely on the morphological expression of aspect and integrate it into lexical aspect in order to mark temporal boundaries. Furthermore, they are confronted to the absence of phonological transparency in the morphology of the present and past in French: silent $e$ or the verb stem in the present, the choice of auxiliaries and the past participle ${ }^{i}$ in the past. Finally, the expression of simultaneity requires syntactic knowledge of both the morphological (the gerund inflection) and the syntactic rules governing their use (subordination). The discourse context must also be a decisive factor in the choice of temporal and aspectual marking. In fact, it is predicted that imperfective marking should be produced primarily with background information while the perfective should be part of the foregrounded information.

Let us turn to two hypotheses that have been proposed regarding the acquisition sequence of tense and aspect. We examine these hypotheses below in light of the diverging characteristics of the two languages examined, particularly, the highly systematic nature of English aspectual-morphology (symetric in the present and past), contrasted with the French marking of aspect (solely marked in the past). The Defective Tense Hypothesis (DTH), first proposed by Bronckart \& Sinclair (1973), suggests that in the process of first 
language acquisition, children use past tense marking to indicate aspect rather than tense, for example associating perfective forms with bounded predicates. Bardovi-Harlig (1999), Bardovi-Harlig \& Reynolds (1995) and Starren (2001) have shown that this hypothesis also applies to L2 acquisition and that therefore the observed associations cannot be attributed uniquely to cognitive development. On the other hand, the Aspect Hypothesis, proposed by Andersen \& Shirai (1994), proposes that L1 and L2 learners are initially influenced by the aspectual semantics of verbs and predicates in the acquisition of tense and aspect markings. As a result, the perfective past is associated with bounded verbs, while the imperfective marking is produced only with unbounded processes. This point remains under debate for L2 acquisition. The participation of English learners of L2 French in our study should allow us to examine the extent to wich uses of tense-aspect marking by learners of a strongly aspectual source language are determined by the semantic aspect of the verbs in a target language that exhibits little morphological marking of aspect.

Linguistic constraints of both languages have a huge impact on learners and require command of the linguistic means of encoding in the spatial and temporal domains. In order to explore these issues, we have examined the acquisition of devices necessary for the expression of temporality (boundaries and simultaneity) and spatiality (motion and change of location) among native speakers of English learning French. These students participated in a task (the "Popi video clips", see below) designed to elicit predicates expressing (voluntary or caused) motion as well as succession and temporal overlap of situations (simultaneity and inclusion). In the task, each participant was asked to describe clips for a "naive" addressee, who did not see them. Our analysis allows us to examine the acquisitional path followed by learners when expressing temporality, specifically, the marking of temporal boundaries and of simultaneity in relation to the expression of motion in the organization of discourse. It is predicted that the typological differences between the two languages should have a strong influence on event descriptions (for research on this subject, $c f$., Hickmann (2003, 2009), Hendriks (2008), Ochsenbauer (2008)). In particular, boundaries can be expressed by particles in English, but depend 
more on the lexical content of verbs in French (specifically, path-verbs). We therefore expected to find evidence for a conflict in the expression of boundaries that the learner must face as a result of this difference.

In English, simultaneity between situations can be expressed by verbal morphology in simple clauses (e.g., (5)). Simultaneity is harder to express in French, particularly in the present, a fact which strongly invites the speaker to use subordination or periphrastic aspectual expressions (e.g., (6)), that are presumably not yet acquired in the early stages of acquisition. These differences lead to the assumption that the learners, who have already acquired their L1, would have difficulties in expressing simultaneity between events, since this requires familiarity with subordination constructions of the target language.

(5) So Hopi pulled the car up the roof at the house. (adult native speaker of English)

(6) Alors Popi monte sur le toit [c] en tirant la voiture de course (adult native speaker of French)

'So Popi climbs on the roof, pulling the race car'

Adopting "the rhetorical bias" of the target language is one of the final stages of L2 acquisition ( $c f .$, Perdue, 1993; Bartning \& Schlyter, 1997; Von Stutterheim, Lambert \& Carroll (2008)). This rhetorical bias requires the acquisition of the discursive functions of the grammatical categories in the target language. In order to ignore the rhetorical bias induced by their L1, learners must develop the capacity to implement new linguistic means, both on the sentence-level and on the discourse level, which may involve a conceptual reorganization (cf. Levelt's model discussed in Perdue, 1993).

\section{Methodology}

\section{Tasks, stimuli and procedure}

The task given to speakers consisted of describing a series of 32 mini-clips, about 4 seconds each, presented on a computer. In each clip, a character (called Popi in French 
and Hopi in English) performed an action that caused the movement of an object while the character was himself in motion ( $c f$. ., Hendriks, Hickmann \& Demagny, 2008). This task required the speaker to mark both boundaries and simultaneity in relation to different types of paths and different manners (manner of action and manner of motion). At the end of each clip, the experimenter gave participants some information (the names of objects and backgrounds), and then asked them to recount what had happened in the clip.

Given the multiplicity of events presented in the stimuli, and the resulting the difficulties facing learners in expressing them all, the experimenter could use general questions to encourage them to continue ("what happened?", "and after?" or "and then?").

\section{Subjects}

Our target groups were composed of two groups of young adult native speakers of English learning French: 12 at an intermediary beginner level, and 12 at a more advanced level. All learners were students at the American University of Paris during the recordings. Therefore, all were studying in a guided environment and in complete immersion in the native country of the target language. Tests for competence levels administered by the University upon registration in their first year (the French Level Exams of the American University of Paris), and students had been regularly tested in order to progress from year to year. At the time of experimentation, they were classified into two levels: intermediate beginner (N1) and advanced intermediate (N2). In addition, control groups of 12 native speakers of French and 12 native speakers of English performed similar tasks. The inclusion of these control groups allowed us to compare the learners' productions in their L2 French with native productions in the source and target languages.

\section{Data}

The recorded data were transcribed and coded using the CHILDES software (McWhinney, 2000). The presented results focus particularly on analyzing the different means used to express temporality in a discourse that involves multiple spatial references 
(locations, motion and changes of location). The analysis includes all types of temporalaspectual distinctions and marking (lexical aspect, verbal morphology, adverbs, subordination), as well as other expressions that are relevant for the representation of spatiality (prepositions, particles, adverbials, subordination), both on the sentence and discourse levels.

Verbs were classified into two categories, following the theories of Vendler (1957) and Klein (1992): verbs expressing states and unbounded activities (Vendler's 'state' and 'activity' verbs, Klein's '0-State' and '1-State' verbs), and verbs expressing bounded activities and/or change-of-state (Vendler's 'accomplishment' and 'achievement' verbs, Klein's '2-State' verbs). Other types of semantic content was also coded: the path of motion (monter 'to climb'), the manner of motion (courir 'to run'), the cause (mettre 'to put') and the manner of action causing motion (pousser 'to push').

Coding takes into account boundaries implied by the verb as well as by other expressions in the verbal network. For example, the French statement alors Popi rentre dans la grotte ('so Popi enters the cave') is coded as containing a verb that expresses an intrinsic boundary, while the English phrasing so Hopi rolled the tire into the cellar is coded as containing a verb that expresses the manner of motion (roll) and a particle (into) that expresses the spatial path and the temporal boundary. Thus, it is possible to determine whether the boundary is encoded in the type of verb or in other linguistic elements produced by the learner.

The morphology was coded according to the forms available in each language for temporal marking (past or non-past) and aspectual marking (perfective, imperfective, unmarked). Some temporal or aspectual markers were coded as indeterminate, especially if they showed ambiguity (e.g., forms that may be either a past participle or an infinitive), as illustrated in the example (5):

(5) il ... [tire] ... avec une ... petite ... chevau ... (Level 1 learner $)^{\mathrm{ii}}$ All other markers that can express temporality (connectives, adverbial expressions) were also coded according to the following semantic criteria: simultaneity (pendant ce temps-là 
'during that time', pendant que 'while'), continuity (toujours 'always'), precedence (avant (que) 'before (that)'), posteriority (après (que) 'after (that)'), inclusion (aussi 'also'), iteration (encore une fois 'again'), duration (un moment 'a moment'), immediacy (à ce moment-là 'at that moment'), temporality (quand 'when') and punctuality (d'un seul coup 'in one stroke/go'). Non-verbal expressions that indicate spatiality have were also coded so as to identify elements that expressed a boundary (e.g. jusqu'en haut 'until the top' in clauses such as (Il monte jusqu'en haut de la colline 'He climbs up to the top of the hill'). Finally, clauses were classified into different types depending on whether they were simplex (independent) or complex with subordination, allowing for the analysis of interclausal relations.

\section{Results}

\section{Morphological marking of time and aspect on the verb}

Figures 1 and 2 show the use of verbal morphology to mark temporal distinctions (past vs. non-past) and aspectual distinctions (perfective vs. imperfective), respectively. Native speakers of English showed much greater use of the past tense, progressive or not, as compared to native speakers of French, who showed a preference for the non-past (présent de l'indicatif), which is not marked for aspect, or for imperfective forms, which are unmarked for temporality (primarily gerunds, 'Other' in Fig. 1 below). Level 1 learners produced in equal proportions present, past and morphologically indeterminate forms (see ex. 5 above), the latter indicating difficulties with the non-transparent morphology of French. In contrast, level 2 learners primarily used forms in the present, similar to the native speakers, demonstrating an emerging control of gerund constructions. (Figures $1 \& 2$ near here)

Fig. 1 Morphological marking of temporality 
Native speakers of French primarily used forms that were unmarked for aspect (66\%) and imperfective forms (25\%). Native speakers of English produced more forms that were either imperfective (43\%) or perfective (55\%), and used unmarked aspectual forms to a much lesser extent than native speakers of French.

Level 1 learners used perfective markings with a frequency that was comparable to the one demonstrated by native speakers of English, a fact which may indicate L1 transfer. However, these speakers did not yet use imperfective markings that would allow the expression of simultaneity in the target language. Consequently, they could not resolve the complex expression of verbal simultaneity highlighted by the task. Level 2 learners were closer to the patterns of French native speakers in their use of the aspectually unmarked present and the perfective past. They also began to use gerund forms (marking imperfect aspect), which enabled them to produce complex structures (main clause and a gerundive subordinate, see also below).

Level 1 learners encountered difficulties using morphology (showing 37\% of indeterminate marking). In this sense they are close to the stage of acquisition called Basic Variety (as defined by Klein and Perdue, 1997), in which morphological marking is ambiguous. In contrast, N3 learners have clearly managed to master their knowledge of the morphology and choose to use the aspectually unmarked present in French. Yet, it is interesting to note an increasing preference for imperfective marking in this task, that systematically required the expression of simultaneity in each item. The linguistic means they used in this case included gerunds and a variety of subordinate constructions, which situated the events in the same temporal region, although they did not always express simultaneity as such (ex. (6) and (7)), as well as temporal adverbs, periphrastic constructions or incomplete subordination markers (ex. (8)), and traces of level 1 attempts to use gerunds, as illustrated in (8) 
(6) Il tire... la... la malle... quand il descend... le... la colline.

(7) M(ainte)nant il... tire un p(e)tite chevaul... chev... pendant il traverse la route.

(8) Il pousse... la cercle... et la cercle... tournu... tourni [tourne]... quand il... il dre(passant)... (dre)passant [traversant ?] ... la rue. (B1\&L05_Janice)

\section{Relations between types of verbs and verbal morphology}

Figure 3 shows the percentages of all morphological markers found in our corpus with bounded and unbounded verbs. The analyis examined wether learners' use of verbal morphology was dependent on the predicate type, in particular in the expression of motion. (Figure 3 near here)

Fig 3 Temporal-aspectual markings as a function of predicate types overall

These figures show that native speakers of English primarily used the past perfective forms with bounded dynamic predicates (89\%), and non-past imperfective ones with unbounded predicates (57\%). This clear correlation between morphology and verb type demonstrates the salience of temporal-aspectual features in English (cf., Smith, 2006). By contrast, native speakers of French had a clear preference for the present form (aspectually unmarked non-past), both with unbounded predicates (58\%) and with unbounded predicates $(61 \%)$, while the imperfective was more common with unbounded predicates $(30 \%)$ than with bounded predicates (18\%). These important cross-linguistic differences suggest that language learners should have difficulties with this system. 
In addition to numerous indeterminate forms, level 1 learners produced perfective past forms with unbounded predicates (33\%) and with bounded predicates $(24 \%)$ in almost equal proportions. This is a typical case of an interlanguage, in which some rules of the target language seem to have been acquired (the aspectually unmarked present), while some rules of the source language are also transferred (such as the the passé composé (perfective past) construction). At this level, learners use the present almost only with bounded verbs (41\% vs. $4 \%$ with unbounded verbs) and ambiguous forms are more frequent with unbounded verbs (59\% vs. $33 \%$ with bounded verbs).

At level 2, the learners' language is closest to native production, particularly through the acquisition of the present morphology. These learners still continue to use unbounded predicates in the passé composé (perfective past), that seem more resistant to acquisition. The fact that their rate of unbounded verbs marked for the perfective (33\%) is higher than for native English speakers does not conclusively support the Aspect Hypothesis (Andersen \& Shirai, 1994), according to which learners use perfective markers with bounded verbs and imperfective markers with unbounded verbs. We will return to this point in the discussion.

\section{Types of event boundaries}

Figure 4 shows the relative use of different procedures to mark boundaries: types of predicates (lexical aspect), morphology (grammatical aspect), other procedures relating to space (such as prepositional expressions and spatial particles) and indeterminate verb forms in the clause. (Figure 4 near here)

\section{Fig. 4 Devices to mark boundaries overall}

The first observation concerns how the expression of boundaries evolves during 
acquisition. In addition to the numerous indeterminate forms already mentioned, level 1 learners tend to express the boundary of events through grammatical aspect (perfective morphology: passé composé), but the use of bounded verbs is also evident, particularly traverser 'to cross', which is most common. Level 2 learners express event boundaries through all linguistic means available (lexical aspect, morphology and spatial prepositional phrases), revealing preferences specific to each learner. Yet, there is an increase in the diversity of bounded verbs such as enterer 'to enter', indicating that their production is gradually becoming more similar to that of native speakers, who tend to express boundaries through lexical aspect.

Still, resistance to the expression of boundaries through prepositional elements remains even after the morphology of the aspectually unmarked present is acquired. The most commonly used prepositions express a path with a goal (e.g., jusqu'à la maison 'up to the house' (ex. 9)). Note in this context the use of expressions whose grammatical function (as verbs or prepositions) is difficult to disambiguate, as illustrated in (10-12) below:

(9) Ok ... il pousse le bouée jusqu' à ... le ..... le ... parte de haut ... de la colline. (Niveau. 1)

(10) Il [rulE] le roue dans - entre le ferme (Niveau 1)

('He rolled the wheel in - enter the barn.' - Lev 1)

(11) Donc il pousse le... le panier de pommes au travers la... la route de... dans une ville... un village.

Popi est $[=$ ?] $\ldots$ [tire $]$ une... popette $[=$ poussette $] \ldots$ uh $[=$ ? a] [travErse $]$ le rue. (Niveau 1)

('Popi is pull(ed) a pram cross(ed) the street.' - Lev 1)

(12) Il a une poussette et il tire une poussette au croisé d(e) le rue... (niveau 2)

('He has a pram and he pulls a pram at-the-crossing of the street ...' - Lev 2) 


\section{Syntactic development}

Figure 5 shows the syntactic properties of subjects' responses, particularly the relative percentage of clauses that involve no subordination (coordinated or independent clauses), as compared to matrix and subordinate clauses (MC and SC) in sentences involving subordination. ${ }^{\text {iii }}$ (Figure 5 near here)

\section{Fig. 5 Utterance types}

Native speakers of French use more complex clauses involving subordination in comparison to native speakers of English. In particular, English speakers primarily use simple, compact structures to express the combination of different types of information, such as the manner of motion encoded in the verb and the path encoded in a satellite (e.g., (12)). French speakers rarely express these two types of information in the same clause, and prefer to use subordination, thus more complex syntactic structures, to mark simultaneity (e.g., (13)). Our results clearly demonstrate the higher frequency of subordinate clauses in French (38\%), including further embedding, as compared to its low frequency in English (6\%).

"eh Hopi rolled the wheel across the road." (English NS)

Popi a traversé la route... la petite rue du village en faisant rouler la roue de charrette. (French NS)

Only 5\% of the productions of level 1 learners involve subordinate constructions. Subordination is particularly difficult for these learners, since it involves the simultaneous mastery of several skills: the use of subordinate conjonctions to express various semantic relations between clauses, additional constraints such as temporal agreement in certain cases, and the appropriate verbal morphology (see Figure 1); this combination poses serious problems at the first level. Given the complexity of subordination, learners establish ways to avoid such grammatical constructions and primarily use independent clauses.

In contrast, level 2 learners have already acquired the principles of verbal morphology in 
the target language, wich enablies them to express simultaneity and to develop subordination ( $c f$., II.2) (23\%). Different types of subordination occurs at this level, particularly clauses marking precedence, simultaneity, co-temporality with the main clause, goal, causality, restrictive and non-restrictive relative clauses, and an additional category including all other cases. As illustrated in examples (14-16), level 2 learners primarily use subordinated gerunds (ex. 14), but also subordination expressing goal (ex, 15), as well as relative clauses expressing repetition, for instance (ex. 16). Since this task strongly invites speakers to express simultaneity, it is quite reasonable that subordination is the primary linguistic method used by level 2 learners, whose performance in this respect is similar to that of the control group of French native speaker. However, these learners use more subordination to express goals as compared to the group of native speakers (10\% more). This type of simple structure is certainly one of the easiest to be implemented by the learner.

(14) heu il traîne le petit cheval en bois ... ahm en traver ... [travErse] traversant la route. main(te)nant il ... pousse la valise pour descendre la colline. il a poussé un ballon qui roule de un colline jusqu'à le bas de la colline.

\section{Analysis of discourse phenomena}

Further analysis examined whether discourse factors played a role in subjects' uses of verbal morphology. In particular, although each experimental item elicited a target reply, many replies took the form of a scenario that included initial events and/or background states ('Beg'), the target response ('Mid') and end-of-scene information ('End'), as in examples (17-18). Figure 6 shows the distribution of morphological markers as a function of these discourse components. 
(17) BEG: There is a big snowy hill. Must be in the Alpes. And Hoppy is on top of the hill.

MID: He rolls a beach ball down the hill.

END: and when he is at the bottom of the hill, he smiles.

(18) BEG: alors c'est Popi dans la forêt

MID: heu, il marche heu, jusqu'à la grotte.

MID: en traînant derrière lui, heu, un caddie.

END: et après il rentre dans la grotte [c].

(Fig. 6 near here)

Fig. 6 The impact of discourse context on time and aspect marking

These results show that discourse context had an impact on uses of verbal morphology. With respect to native speakers, figure 6 shows cross-linguistic differences. While English speakers use the present simple primarily in background descriptions, target responses are frequently in the present progressive (51\%) and in the simple past (31\%), while the use of the simple past is predominant in responses providing end-of-scene information (73\%). French speakers primarily use the unmarked present, regardless of discourse context, except for the use of gerund constructions, required by the task, in the target responses.

The responses of level 1 learners show similarities with both native groups, reinforcing the results described above regarding the interlanguage stage. Indeed, while background responses are mainly in the aspectually unmarked present (61\%) (as found with native speakers of French), end-of-scene responses are marked as perfective through the use of the passé composé (80\%), a result that is closer to the productions of native speakers of English. Target responses present more significant morphological difficulties and no specific temporal or aspectual marking is particularly evident. 
Level 2 learners are much closer to the native speakers of French in their frequent use of the aspectually unmarked present. Note, however, the emergence of gerunds that allows them to express imperfective aspect as well as its simultaneity among events.

The following examples illustrate these results.

\section{Native speakers of English:}

(19) $\mathrm{Mr}$ Hoppy is in a village $[=B E G]$, he' s pulling the pram across the road to the other side of the road $[=M I D]$ and stopped with it $[=E N D]$.

\section{Native speakers of French:}

(20) Donc Popi est en haut de la colline $[=B E G]$, il pousse la grosse valise jusqu' en bas de la colline en la faisant glisser heu jusqu' au bas de la colline $[=M I D]$ et il s'arrête $[=E N D]$.

('So Popi is on top of the hill $[=B E G]$, he pushes the big suitcase until the bottom of the hill by making it slide heu until the bottom of the hill $[=M I D]$ and he stops $\left.[=E N D]^{\prime}\right)$

\section{Level 1 learners}

(21) Il commence ... sur ... l'hor [: haut $]$... du le montagne $[=B E G]$, il est poussé le bôle [: balle] sur le ...montagne de neige $[=M I D]$ et ... il a fini ... à la fin de la montagne $[=E N D]$.

('He starts on the top of the mountain $[=B E G]$, he is[=has] pushed the ball on the snow mountain $[=M I D]$ and he finishes at the end of the mountain [=END].')

\section{Level 2 learners}

Il est dans un village $[=B E G]$, il traîne la poussette $\ldots$ en traversant la rue $\ldots[=M I D]$, donc il monte le trottoir, après $[=E N D]$.

(He is in a village $[=B E G]$, he is dragging the pushchair ... in crossing the street $\ldots[=M I D]$, so he is climbing up the pavement after $[=E N D]$.) 


\section{Discussion}

This study examined the use of various linguistic methods to express temporality among adult native speakers of English learning French at two levels of competence, in an environment of guided immersion, in comparison to the production of native speakers (of English and of French). The same task was used in all groups allowing direct comparisons of how speakers expressed temporality when describing motion in space. While each of the languages examined provides a range of means to express the same spatial and temporal distinctions, they also display striking differences. This study was designed to determine the impact of these differences on the acquisitional path.

In the spatial domain, English, (satellite-framed language), expresses the manner of motion in the verb root and the path in satellites; in French, (verb-framed language), the path is encoded through the lexical content of the verb, but the manner of motion is either not expressed, or expressed through peripheral devices. In the temporal domain, English presents a systematic aspectual opposition between progressive and non-progressive markers, while no aspectual opposition is marked in French verbal morphology in the present, forcing learners acquire periphrastic constructions.

At level 1, the learner's language displays properties of both the source language and the target language. Differences between the two languages are particularly evident in our results in two ways: i) a clear relationship in English between morphology and verb types, which is not found in French, where the aspectually unmarked present is used regardless of lexical aspect; ii) the impact of the discourse context on the use of temporal and aspectual marking.

At level 1, learners can express temporal boundaries through grammatical aspect, but forms that are morphologically indeterminate remain most frequent. However, the perfective past is used with bounded verbs, indicating that the lexical properties of verbs contribute to the expression of temporal boundaries. Moreover, these boundaries are primarily associated with utterances describing end-of-scene elements, thus demonstrating the impact of discourse factors. 
These learners primarily use perfective forms, since they do not yet know how to express the imperfective aspect at this stage. This difficulty is partly due to their syntactic ability at this stage, which enables the production of independent simplex clauses, but does not extend to subordination that allows the use of the French imperfective gerund.

The most notable change in the language of level 2 learners is the use of an additional means of marking boundaries, namely the use of lexical aspect (with bounded verbs). The morphology of the French present is well acquired at this stage, as indicated by the significant decrease in the use of indeterminate forms as compared to level 1 learners. Use of the imperfective is growing, but this construction is still used less frequently, even by advanced learners, as compared to native speakers of French. This remains a rhetorical bias of the target language that must be developed in later stages of acquisition. Finally, mastery of the target syntax is much more extensive, and includes subordinate constructions. Thanks to this range of linguistic means, simultaneity can be expressed, even through the forms chosen are not always correct, as shown by the absence of the preposition en 'in/while' before gerunds and in the use of a subordinator expressing simultaneity (quand 'when') or goals (pour 'for' + infinitive).

Level 1 learners have retained some specific features of their L1, especially in the marking of temporal and spatial boundaries. They have not yet acquired the morphological marking of the target language and their output shows many cases of L1 transfer. Gass and Selinker (1994) describe the psychological process by which knowledge of an initial learning situation is used in a new learning situation. Interference of the source language is common among learners, regardless of their level of competence, in the temporal-aspectual morphology of the source language or in the expression of manner through the verb and of the path through satellites. Nonetheless, the results indicate a progression between the two levels, despite the fact that learner's language still show properties of both source and target languages. The impact of L1 appears to be particularly strong with respect to the discourse context and the lexical properties of the verb. 
The verbal morphology of level 2 learners is less influenced by the verb types, and clear progress is sown by the use of the aspectually unmarked present with both bounded and unbounded verbs. In addition, imperfective markers emerge, coupled with an increase in syntactic complexity. There is, therefore, a development in the expression of simultaneity and of temporal boundaries.

In conclusion, we ca see the impact of various factors on two levels of linguistic organization, the sentence and discourse, in the course of L2 acquisition: the type of predicate plays a role on the clause level and the anchoring of information is determined on the level of discourse. The effect of language-specific properties only provides partial support for the Aspect Hypothesis. Consequently, cross-linguistic variability as well as different levels of competence and different levels of linguistic organization must be taken into account in the examination of this hypothesis.

Our study shows a development in how adult learners mark boundaries when expressing motion during the process of L2 acquisition. According to our interpretation of the results, typological differences between the source and target languages (English and French respectively) should lead to a re-conceptualization during acquisition, a process that is probably cognitively taxing. This interpretation is supported by the fact that English-speaking learners have difficulties in expressing some types of information in L2 French, such as the path in the verb, and continue to mark event boundaries through satellites, although they manage to mark some boundaries by lexical means. Spatial satellites remain their preferred means of micro-planning in L2 French. In contrast, organizing information in discourse like native speakers, requires complex means, such as the use of subordination, particularly for the expression of simultaneity. During the process of re-conceptualization necessary in the acquisition of a foreign language, learners import and overgeneralize linguistic means from their source language, encoding information for which they lack the means in the target language, notably in the expression of perfectivity. The imperfective gerund in the target language (French), requires complex constructions both on the level of macro-planning and on the level of micro-planning. Learners must therefore acquire both the appropriate morphology and the 
corresponding subordination that are needed in L2, which take longer to learn. Future studies will examine in more detail other relevant discourse contexts and other types of linguistic means used to mark temporal boundaries and simultaneity (such as adverbs and connectors). In addition, the role of cognitive development in this process will be examined through a comparison of adult L2 learners with monolingual children. 


\section{References}

Andersen R. W. and Shirai Y. (1994) Discourse motivations for some cognitive acquisition principles. Studies in Second Language Acquisition 16: 133-156.

Andersen R. W. and Shirai Y. (1996) Primacy of aspect in first and second language acquisition: The pidgin/creole connection. In W. C. Ritchie and T. K. Bhatia (Eds), Handbook of second language acquisition (pp. 527-570). San Diego, CA: Academic Press.

Bardovi-Harlig, K. (1999) From morpheme studies to temporal semantics - Tense-aspect Research. Studies in Second Language Acquisition, 21:341-382.

Bardovi-Harlig, K. and Reynolds, D. W. (1995) The role of lexical aspect in the acquisition of tense and aspect. TESOL Quarterly, 29, pp. 107-131.

Bardovi-Harlig, K. (2000) Tense and aspect in second language acquisition: Form, meaning, and use. Oxford: Blackwell.

Bartning, I. and Schlyter, S. (2004) Itinéraires acquisitionnels et stades de développement en français L2. Journal of French language Studies 14:3, 281-299. Cambridge University Press.

Bronckart, J. P. and Sinclair, H. (1973) Time, tense and aspect. Cognition 2:107-130.

Carroll M., Natale S. and Starren M. (2008) Acquisition du marquage du progressif par des apprenants germanophones de l'italien et néerlandophones du français. Aile 26:31-50.

Dietrich, R., Klein, W. and Noyau C. (1995) The acquisition of temporality in second language. Amsterdam: John Benjamins.

Dimroth, C. and Lambert, M (2008) La structure informationnelle chez les apprenants L2. Aile 26, 11-29.

Gass, S. and Selinker, L. (1994) Second Language Acquisition. Hillsdame, NJ : Lawrence Erlbaum.

Hendriks H., Hickmann M. and Demagny A.-C. (2008) How adult English learners of French express caused motion: A comparison with English and French natives. Aile 27:15-41. 
Hickmann, M. and Taranne P. and Bonnet P. (2009) Motion in first language acquisition: Manner and Path in French and English child language. Journal of Child Language $36: 705-741$.

Hickmann, M. (2003) Children's discourse:Person, Space and Time across Languages. Cambridge: Cambridge University Press.

Klein, W. (1992). Time in Language. London: Routledge.

Klein, W. and Perdue, C. (1997) The Basic Variety (or Couldn't natural languages be much simpler ?). Second language Research 13, 301-347.

Lambert, M., Carroll M. and von Stutterheim, C. (2008) Acquisition en L2 des principes d'organisation de récits spécifiques aux langues. Aile 26:11-29.

Mc Whinney, B. (2000) The CHILDES Project: Tools for Analyzing Talk. 3rd Edition.

Mahwah, NJ: Lawrence Erlbaum Associates.

Meisel, J. M. (1987). Reference to past events and actions in the development of natural second language acquisition. In C. W. Pfaff, (Ed.) First and second language acquisition (pp. 206-224). New York: Newbury House.

Ochsenbauer, A-K. (2008) The expression of caused motion in German in French : New insights form L1 acquisition. Exposé le 9 juillet 2008 à la 5th International Contrastive Linguistic Conference, Louvain.

Perdue, C. (Ed.) (1993) Adult language acquisition: cross-linguistic perspectives. Cambridge: Cambridge University Press.

Riegel, M., Pellat, J.-C. and Rioul, R (1999). Grammaire méthodique du français. PUF, Paris.

Shirai, Y. and Kurono, A. (1998). The acquisition od Tense-Aspect marking in Japanese as a Second Language. Language Learning 48(2):245-279.

Smith, C. (2006) The pragmatics and semantics of temporal meanings. In P. Denis, E. McCready, A. Palmer and B. Reese (eds) Proceedings, Texas Linguistics Forum 2004. Cascadilla Press.

Starren, M. (2001) The second time: the acquisition of temporality in Dutch and French as a second language. Utrecht: LOT. 
Talmy, L. (2000) Towards a Cognitive Semantics. Harvard: MIT Press.

Vendler, Z. (1967) Linguistics in Philosophy. Ithaca, New York: Cornell University Press. 
${ }^{\mathrm{ii}}$ For example: Linda monte sur une colline, est montée sur une colline, a monté une colline, a descendu une colline.

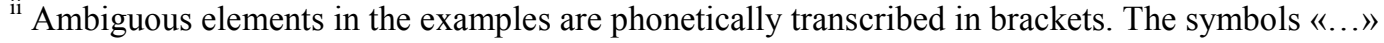
represent pauses.

iii A matrix clause may contain one or many subordinate clauses.

Fig. 1 Morphological marking of tense

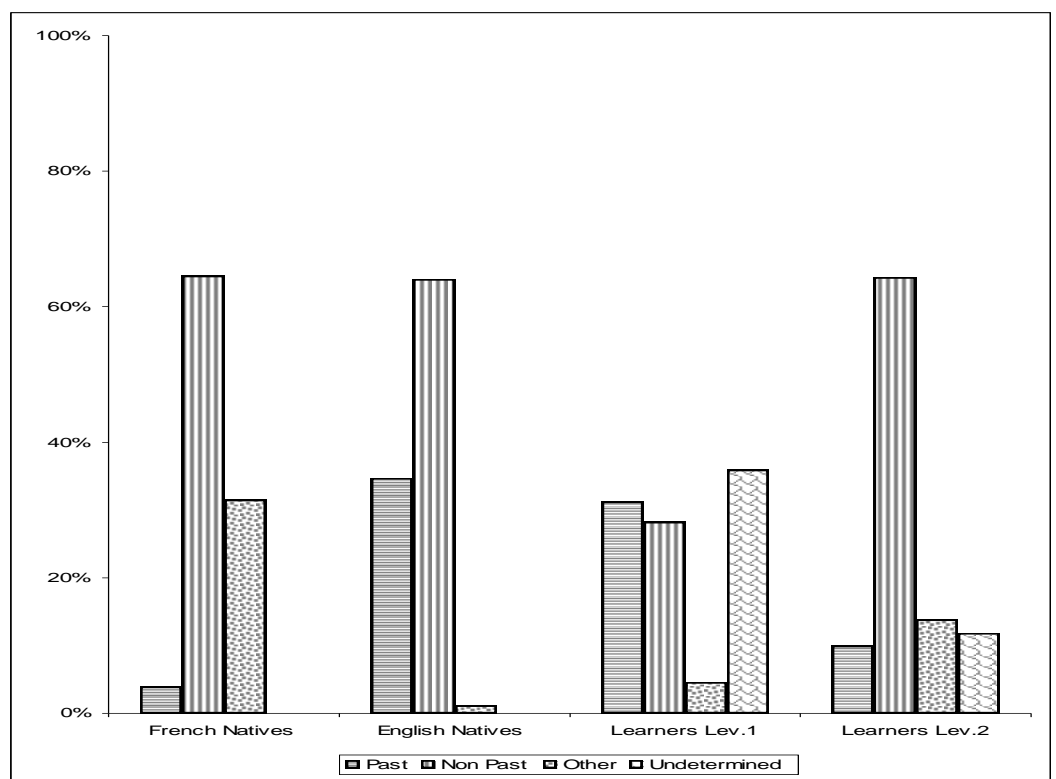

Fig. 2 Morphological marking of aspect

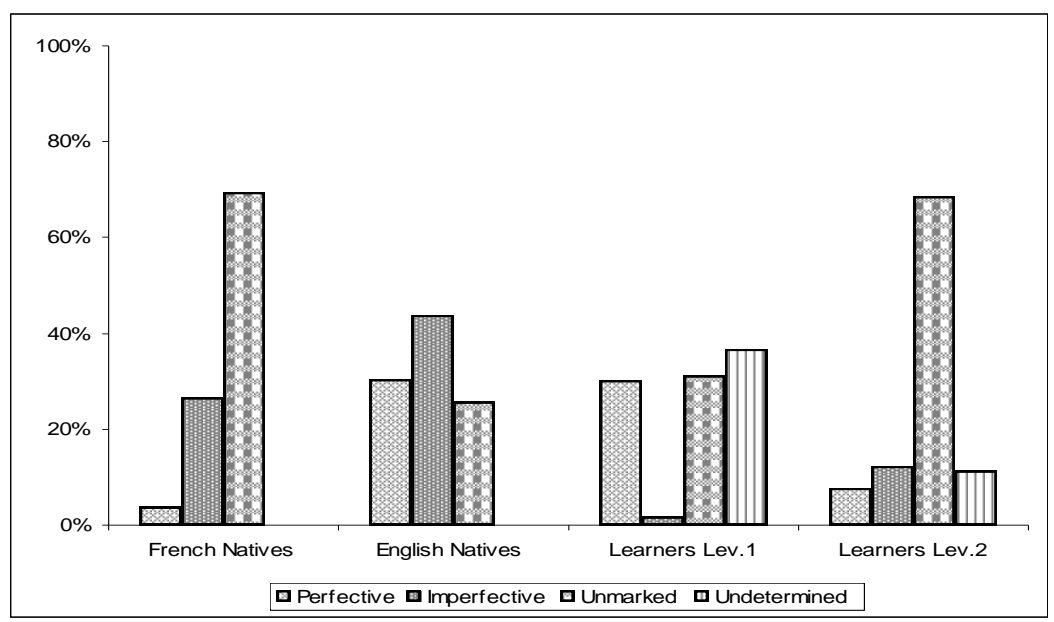


Fig. 3 Temporal-aspectual markings as a function of predicate types overall
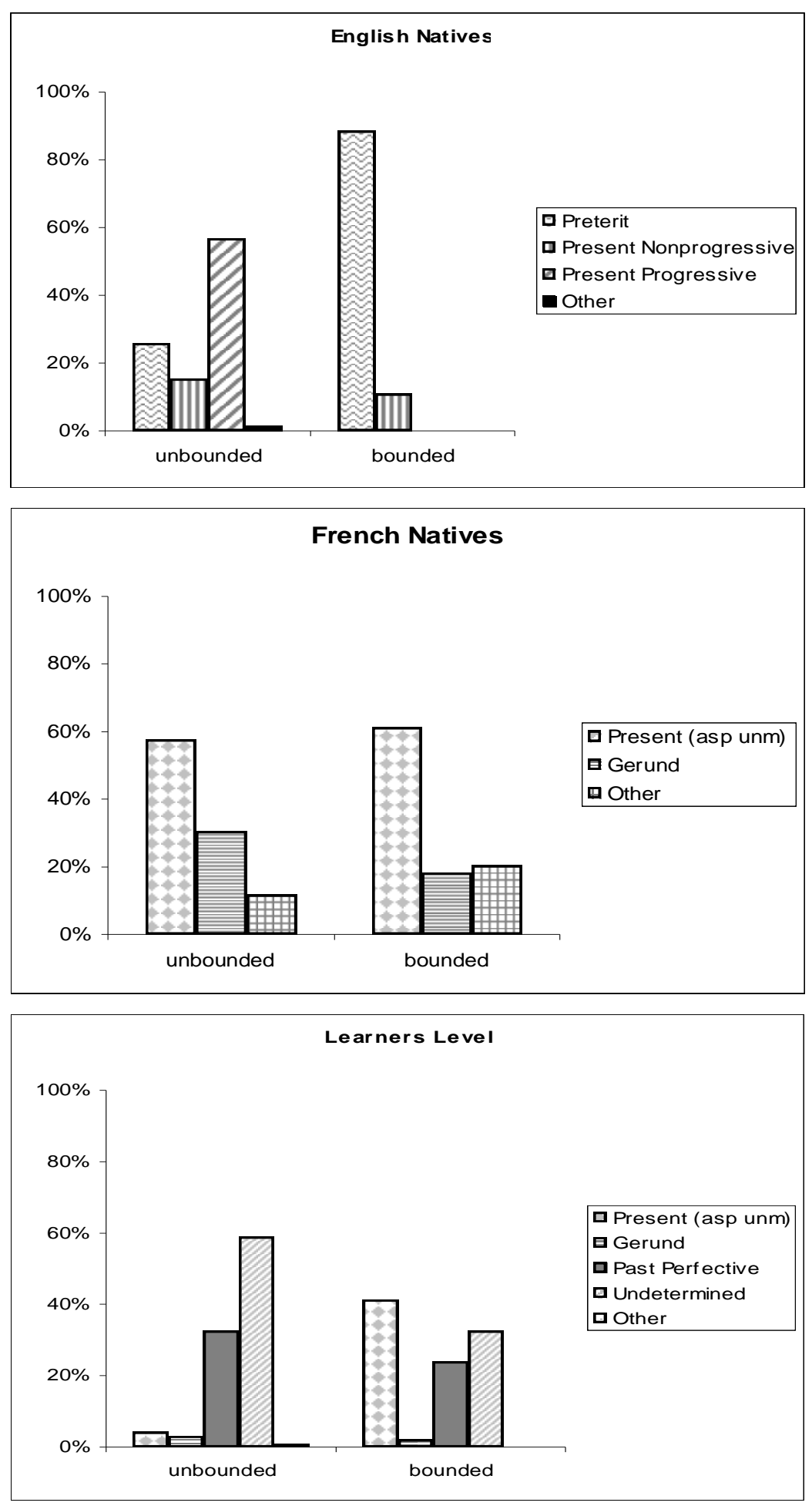


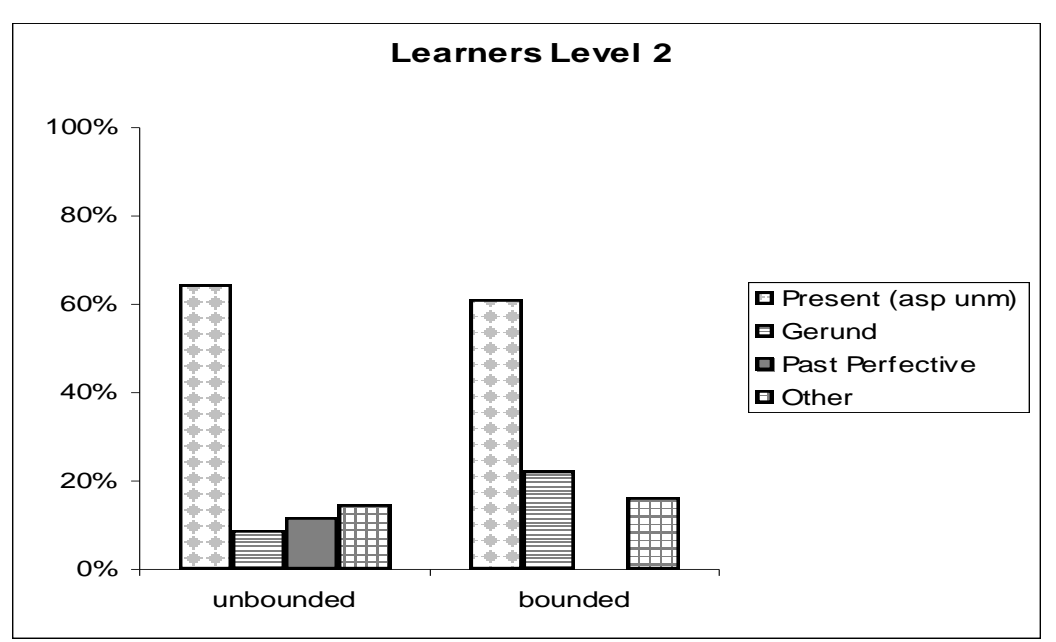

Fig. 4 Devices to mark boundaries overall

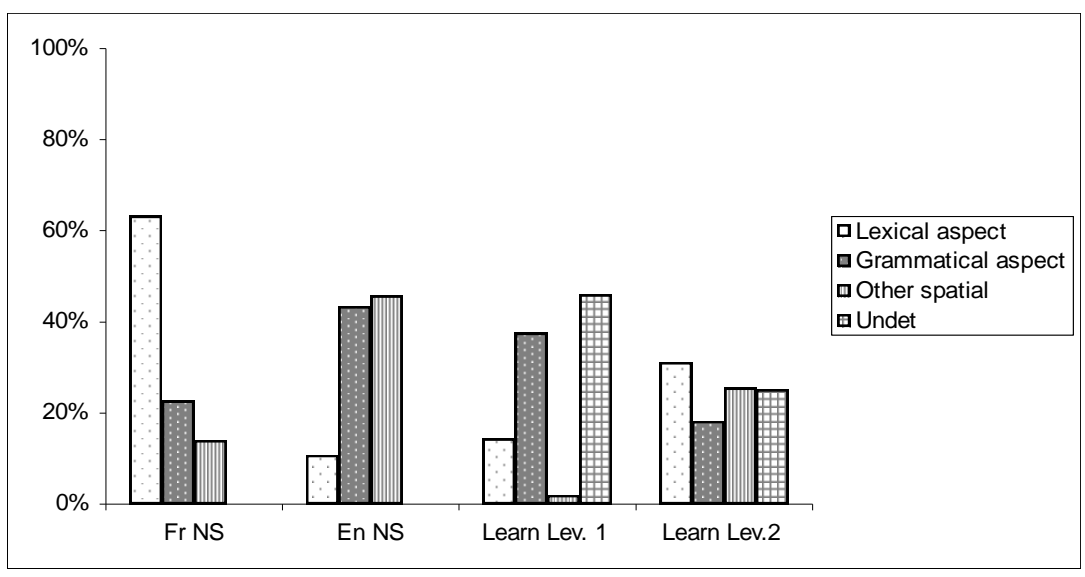

Fig. 5 Utterance types

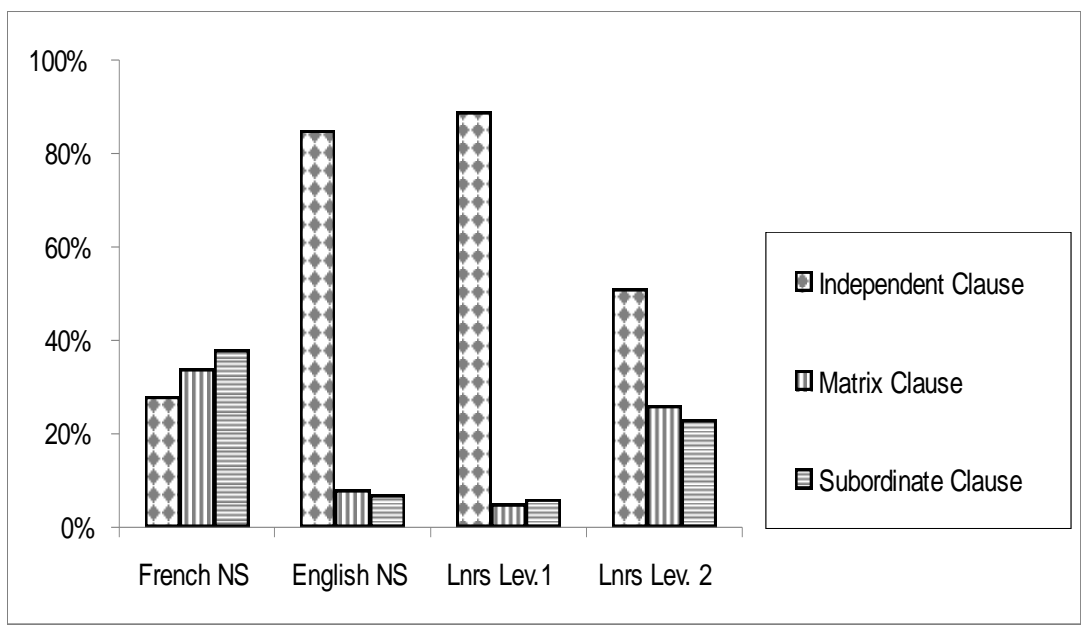


Fig. 6 The impact of discourse context on time and aspect marking
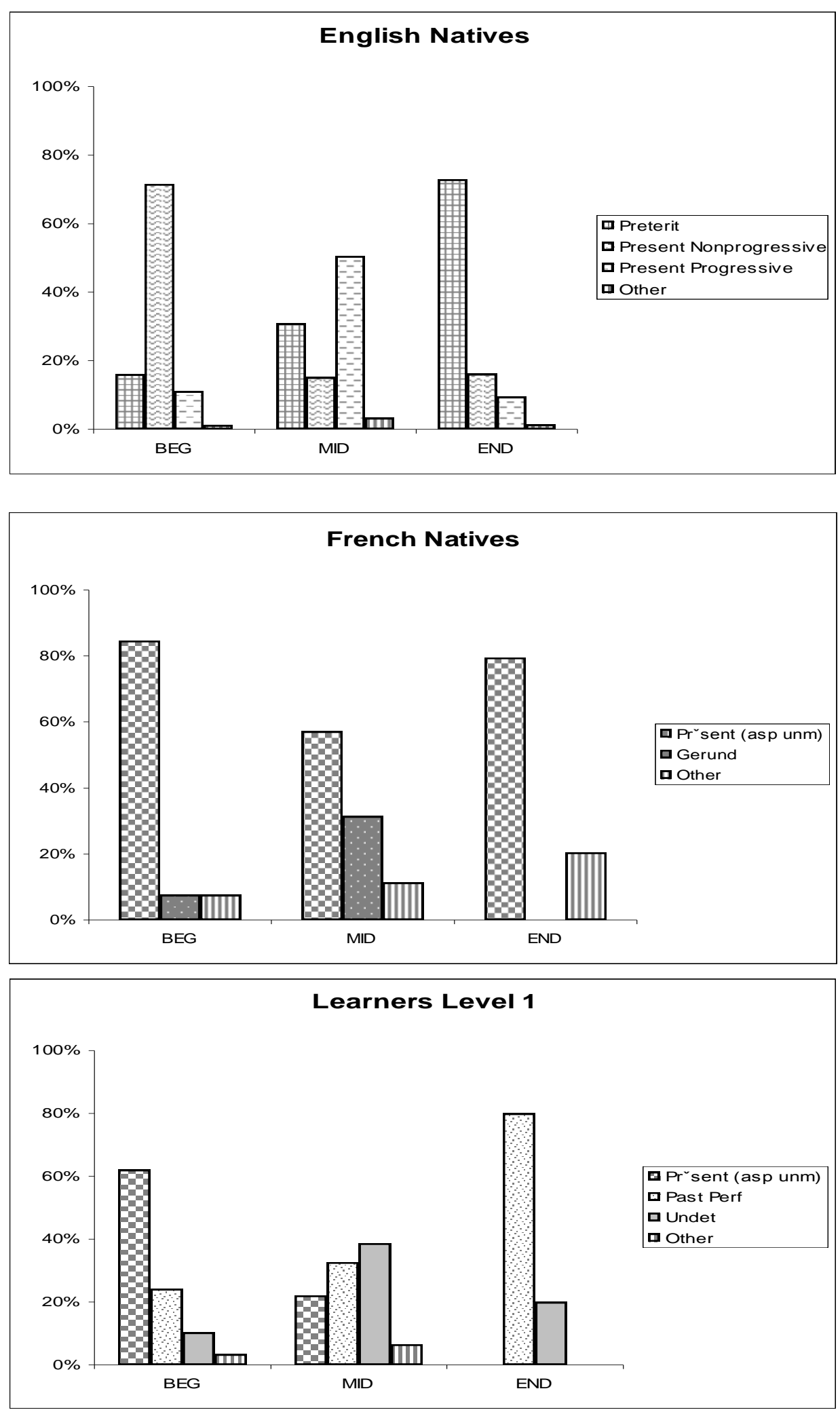


\section{Learners Level 2}



